\title{
REPRESENTASI BUDAYA PADA WACANA TULIS PELAJAR CRITICAL LANGUAGE SCHOOLARSHIP
}

\author{
Azza Aulia Ramadhani \\ IKIP Budi Utomo Malang \\ azzauliaramadhani@gmail.com
}

\begin{abstract}
Abstrak
Seiring dengan berkembangnya zaman, semakin berkembang pula minat orang asing untuk mempelajari bahasa dan budaya Indonesia. Meskipun yang dipelajarinya adalah bahasa Indonesia, pelajar asing tetap tidak bisa meninggalkan budaya yang berasal dari tempat tinggalnya karena itu adalah identitasnya. Hal tersebut tercermin pada wacana tulis yang dihasilkannya, baik dalam menulis karangan bebas maupun dalam menulis karangan terpadu. Tujuan penelitian ini untuk mengetahui representasi budaya yang tampak pada tulisan pelajar asing yang mengikuti program Critical Language Scholarship. Data dikumpulkan dengan dokumentasi, kemudian data dianalisis dengan teknik deskriptif dan kualitatif. Hasil peneitian ini adalah ditemukannya representasi budaya pada tulisan pelajar asing yang mengikuti program CLS.
\end{abstract}

Kata Kunci: representasi budaya, wacana tulis, BIPA

\section{CULTURE REPRESENTATION IN WRITING DISCUSSION LEARNING CRITICAL LANGUAGE SCHOLARSHIP}

\begin{abstract}
Along with the flies of the times, the interest of foreigners is also growing to learn Indonesian language and culture. Although what they learned was Indonesian, foreign students still could not leave the culture that came from their place of residence because that was their identity. This was reflected to the written discourse they produced, both in writing free writing and in writing integrated essays. The purpose of this study is to find out the cultural representation that appears in the writings of foreign students who take the Critical Language Scholarship program. Data was collected with documentation, then the data were analyzed with descriptive and qualitative techniques. The results of this study are the discovery of cultural representations in the writings of foreign students participating in the CLS program.
\end{abstract}

Keyword: representation, culture, writing

\section{PENDAHULUAN}

Semakin banyak orang asing yang tertarik untuk belajar bahasa Indonesia, tentunya semakin banyak pula penelitian yang dilakukan untuk mengkaji pemerolehan bahasa orang asing. Pembelajaran bahasa Indonesia bagi penutur asing (BIPA) berbeda dengan pembelajaran bahasa Indonesia pada umumnya 
karena pembelajaran BIPA lebih menekankan kemampuan komunikatif pembelajarnya.

\section{Berkaitan} dengan pembelajaran bahasa, baik itu pembelajaran bahasa Indonesia bagi penutur asing maupun pembelajaran bahasa Indonesia pada umumnya. Pembelajaran bahasa tidak lepas dari keterampilan berbahasa yang dimiliki seseorang. Keterampilan berbahasa yang dimaksud terdiri atas empat aspek yang meliputi (a) keterampilan menyimak atau listening skill, (b) keterampilan berbicara atau speaking skill, (c) keterampulan membaca atau reading skill, dan (d) keterampilan menulis atau writing skill. Keterampilan menyimak atau listening skill dan keterampilan membaca atau reading skill termasuk dalam keterampilan reseptif, sedangkan keterampilan berbicara atau speaking skill dan keterampilan menulis atau writing skill termasuk dalam keterampilan produktif. Baik belajar bahasa untuk tujuan khusus (BIPA) maupun belajar bahasa Indonesia untuk tujuan umum, bahasa Indonesia dipelajari dan digunakan sebagai alat. Bahasa Indonesia difungsikan sebagai alat komunikasi baik secara lisan maupun tulis. Oleh karena itu, dalam pembelajaran BIPA, tujuan utama yang ingin dicapai adalah kemampuan pembelajar untuk berkomunikasi dengan menggunakan bahasa Indonesia yang dipelajarinya. Dengan demikian, pembelajar diharapkan dapat memiliki kemampuan komunikatif (Suyitno, 2004:17).

Sebelum seseorang menjadi dwibahasawan, selama proses penguasaan B2 berlangsung sering terjadi pencampuradukan antara kode B1 dengan B2 dalam berkomunikasi menggunakan B2, pencampuradukan kode tersebut dapat berupa interferensi maupun campur kode. Meskipun demikian, hal ini sangat wajar dialami oleh semua pembelajar B2. Gejala terjadinya pencampuradukan antara kode $\mathrm{B} 1$ dengan $\mathrm{B} 2$ disebut bahasa antara (interlanguage).

Bahasa antara adalah bahasa yang dihasilkan oleh seorang pembelajar B2 yang sedang dalam proses belajar untuk menguasai bahasa sasaran. Pada tahap awal, bahasa antara pembelajar B2 masih 
didominasi oleh pemakaian kode bahasa pertama. Secara bertahap, perlahan-lahan pemakaian bahasa pembelajar akan didominasi oleh pemakaian kode B2 dan bahkan pada akhirnya akan mencapai titik penguasaan koordinatif.

Seperti yang sudah dijelaskan di atas, di dalam bahasa antara pembelajar banyak terjadi interferensi ataupun campur kode. Interferensi adalah kesulitan tambahan dalam proses menguasai bunyi, kata atau konstruksi bahasa kedua sebagai akibat adanya perbedaan antara B1 dan B2 sehingga kebiasaan berkomunikasi dengan B1 terbawa saat berkomunikasi dengan menggunakan B2, atau sebaliknya. Beberapa ahli berpendapat bahwa interferensi ini selalu bersifat individual dan tidak menentu, artinya bahwa kesulitan tambahan yang terjadi pada seorang pembelajar B2 yang satu akan berbeda dengan pembelajar B2 yang lain.

Interferensi juga sering dialami oleh pelajar asal Amerika yang mengikuti program Critical Language Scholarship (CLS).
Critical Language Scholarship adalah salah satu program kerja sama dengan Universitas Negeri Malang untuk mahasiswa Amerika yang belajar BIPA di Universitas Negeri Malang.

Seorang pembelajar B2, seringkali terpengaruh oleh B1 saat berkomunikasi ketika mereka masih sedang dalam proses belajar untuk menguasai B2. Pengaruh tersebut dikenal dengan istilah interferensi. Interferensi dapat terjadi baik dalam komunikasi lisan maupun tulisan. Oleh karena itu, pelajar CLS juga sering mengalamai interferensi saat menulis karangan dalam bahasa Indonesia yang merupakan bahasa sasaran mereka.

Ada beberapa faktor yang menyebabkan terjadinya interferensi, misalnya saja karena pembelajar B2 belum menguasai bahasa sasaran. Selain itu, bisa juga disebabkan oleh latar belakang budaya yang berbeda antara bahasa pertama pembelajar dengan bahasa sasaran.

Representasi budaya dalam wacana tulis pelajar CLS tampak pada kalimat-kalimat yang dihasilkannya dalam menulis 
karangan. Wacana tulis ini diambil dari hasil Ujian Tengah Semester. Pada Ujian Tengah Semester, para pelajar CLS diminta untuk menulis karangan tentang pengalaman yang paling menarik selama mereka berada di Malang. Pada wacana tersebut, banyak sekali interferensi yang ditemukan. Interferensi tersebut terjadi karena pelajar CLS masih belum menguasai bahasa Indonesia yang merupakan bahasa sasaran sehingga mereka menulis karangan dengan menggunakan bahasa antara. Kalimat yang ditulisnya bahasa Indonesia, namun sruktur kalimatnya masih berupa struktur bahasa Inggris. Selain itu, interferensi juga bisa terjadi karena latar belakang budaya B1 dan B2 yang berbeda sehingga pelajar CLS tidak memiliki fitur semantik yang memadai untuk mendeskripsikan hal-hal tertentu.

Selama dalam proses belajar untuk menguasai B2, pembelajar seringkali mencampuradukkan kode B1 dengan B2 saat berkomunikasi dengan menggunakan B2, baik berupa interferensi maupun campur kode. Walaupun demikian, hal tersebut sangatlah wajar dialami oleh pembelajar bahasa asing. Gejala yang terjadi itu disebut dengan bahasa antara atau interlanguage. Di dalam bahasa antara pembelajar banyak terjadi interferensi ataupun campur kode. Interferensi merupakan perubahan sistem suatu bahasa sehubungan dengan adanya persentuhan bahasa tersebut dengan unsur-unsur bahasa lain yang dilakukan oleh penutur bilingual. Singkatnya, interferensi dipahami sebagai sistem bahasa tertentu yang mengacaukan sistem bahasa lainnya baik dari segi fonologi, morfologi, dan sintaksis. Interferensi ini sering terjadi pada pelajar CLS yang sedang dalam tahap menguasai B2. Oleh karena itu, bahasa antara yang dihasilkan oleh pelajar CLS masih terpengaruh oleh struktur bahasa pertamanya yang merupakan bahasa Inggris. Tak jarang pula interferensi yang dialami oleh pelajar CLS terjadi karena perbedaan latar belakang budaya antara budaya Amerika dengan budaya Indonesia sehingga pelajar CLS kurang tepat dalam memilih kata untuk mendeskripsikan sesuatu yang merupakan ciri khas budaya Indonesia. 
Relativitas bahasa dan relativitas budaya merupakan topik lama yang tetap menarik. Dalam dua bab terakhir dari bukunya Language, Sapir membahas kaitan tak langsung antara bahasa dan budaya, serta kekhasan bentuk sastra yang tergantung pada kekhasan struktur bahasa yang menjadi wahananya. Dalam aliran strukturalisme Amerika, perbedaan lintas-bahasa yang dinyatakan oleh Joos maupun Moulton terutama meliputi perbedaan struktur bahasa pada tingkat fonetik, fonemik, morfemik, dan sintaktik. Kuatnya keyakinan terhadap relativitas bahasa tersebut mendorong munculnya gagasan tentang analisis kontrastif dalam pengajaran bahasa asing, yang dipelopori oleh Fries dan kemudian dipopulerkan oleh Lado (Kadarisman, 2009:14). Artinya, relativitas bahasa, yang merupakan simpulan analisis linguistik murni, jadi menonjol secara amat jelas di bidang linguistik terapan dengan adanya ungkapan: every language is structurally unique.

Hudson (dalam Kadarisman, 2009:15) menjelaskan bahwa bahasa tercakup dalam budaya. Oleh karena itu, tuturan dalam komunikasi verbal sering mencerminkan, secara langsung maupun tak langsung, nilai-nilai budaya yang dianut oleh penutur suatu bahasa.

Kemudian, bagi pendekatan yang melihat bahasa sebagai cermin masyarakat atau budaya, definisi bahasa yang sesuai adalah paduan antara definisi Sapir (dalam Kadarisman, 2009:16) dan definisi Francis (dalam Kadarisman, 2009:16).

Language is a system of arbitrary vocal or visual symbols used by people of a given culture as a means to carry on their daily affairs. (Bahasa adalah sistem verbal atau visual bersifat manasuka, yang digunakan oleh sekelompok penutur dengan budaya tertentu, sebagai alat komunikasi dalam kehidupan mereka sehari-hari).

Definisi ini menegaskan bahwa konsep-konsep budaya mungkin sekali bersifat khusus dan muncul secara jelas lewat ekspresi bahasa. Hal tersebut tampak pada wacana tulis yang dihasilkan oleh pelajar CLS. 


\section{METODE}

Penelitian

Representasi

Budaya pada Wacana Tulis Pelajar

Critical Language Schoolarship ini merupakan jenis penelitian kualitatif. Pendekatan kualitatif dalam penelitian ini didasarkan dua pertimbangan. Pertama, penelitian ini bersifat induktif, yaitu pengembangan konsep didasarkan data yang ada. Kedua, penelitian ini bersifat deskriptif, artinya penelitian berusaha membuat deskripsi secara sistematis, faktual dan akurat mengenai fakta-fakta, sifat-sifat, serta hubungan antar fenomena yang diselidiki. Hal tersebut sejalan dengan pendapat Hasan (1990:16) yang menyatakan bahwa penelitian kualitatif selalu bersifat deskriptif, artinya data yang dianalisis dan hasil analisisnya berbentuk deskripsi fenomena, tidak berupa angkaangka atau koefisien tentang hubungan antarvariabel. Oleh karena itu, instrumen penelitian dalam penelitian ini adalah peneliti sendiri yakni, peneliti sendiri yang berperan sebagai observer dan juga penganalisis data.

Data dalam penelitian ini berupa kalimat yang terdapat dalam karangan mahasiswa program CLS di Fakultas Sastra UM. Kalimat pada karangan tersebut diklasifikasikan dalam pengaruh budaya yang tampak pada hasil tulisan pelajar asing.

Sumber data penelitian ini adalah karangan mahasiswa program CLS di Fakultas Sastra UM. Data penelitian ini berupa karangan mahasiswa asing dari Amerika pada program CLS di Fakultas Sastra UM, khususnya yang berada di kelas intermediate. Kelas intermediate sendiri dibagi lagi menjadi tiga tingkatan, yaitu tingkat low intermediate (5 mahasiswa), intermediate (4 mahasiswa), dan high intermediate (4 mahasiswa). Penelitian Representasi Budaya pada Wacana Tulis Pelajar Critical Language Schoolarship ini menggunakan studi dokumentasi dengan mengumpulkan karangan-karangan mahasiswa asing yang telah ada.

Instrumen yang digunakan dalam penelitian ini adalah peneliti sendiri sebagai instrumen kunci. Selain itu, peneliti juga menggunakan instrumen pembantu 
yang berupa tabel spesifikasi dan tabel analisis data.

Analisis data dalam penelitian ini dilakukan dengan tahap pengidentifikasian, yaitu peneliti mengindentifikasi data karangan mahasiswa asing dengan jalan menyeleksi dan memilih data yang benar-benar layak digunakan. Hal ini dilakukan peneliti agar dalam pengklasifikasian data tidak

\section{HASIL DAN PEMBAHASAN}

Berikut adalah hasil analisis terhadap kalimat yang ditulis oleh pelajar CLS.

(1) Walaupun ada beberapa istirahat setiap hari, saya pikir pendidikan di pesantren ini sulit sekali. $\mathrm{RK} / \mathrm{P} 2 / \mathrm{K} 3$

(2) Hanya ada satu liburan setahun untuk satu bulan. RK/P2/K4

\section{Pada kalimat (1) dan (2)} dapat dilihat bahwa pelajar CLS mengalami interferensi. Pada kalimat (1), dapat dilihat pada konstituen "saya pikir" bahwa pelajar CLS terpengaruh oleh struktur bahasa pertamanya yang merupakan bahasa Inggris. Konstituen "saya pikir" merupakan ditemukan hambatan yang dapat mengurangi validitas hasil analisis. Kemudian, kode yang digunakan meliputi menyebutkan (1) inisial nama mahasiswa (karangan yang diteliti) serta sumber penelitian dari karangan UTS dan UAS, (2) nomor paragraf, dan (3) nomor kalimat. Lalu tahap terakhir yang dilakukan peneliti adalah klasifikasi data.

padanan dari bahasa Inggris "I think". Pada konstituen "saya pikir" juga nampak bahwa pelajar CLS masih terbawa oleh budaya barat yang selalu lugas dalam menyampaikan pendapat sehingga pelajar CLS tidak ragu dalam mengungkapkan pendapatnya terhadap suatu fenomena dengan menggunakan padanan "I think". Sama halnya pada kalimat (2), nampak pada konstituen "satu liburan setahun untuk satu bulan" bahwa penulis masih terpengaruh oleh struktur bahasa pertamanya. Bagi penutur asli bahasa Indonesia, konstituen "satu liburan setahun untuk satu bulan" tidak berterima karena konstituen tersebut bukan merupakan struktur kalimat dalam 
bahasa Indonesia, melainkan bahasa Inggris yang bila diterjemahkan menjadi "There is only one holiday a year for one month".

(3) Pendidikan seni di Indonesia adalah kurang formal daripada pendidikan seni di Jepang dan Amerika. MI/P1/K4

(4) Di kelompok karawitan seperti Titia Laras, biasanya ada banyak orang yang tua dan sudah pernah bermain karawitan banyak tahun. MI/P1/K7

Tidak jauh berbeda dengan kalimat (1) dan (2), pada kalimat (3) dan (4) pelajar bahasa asing juga mengalami interferensi karena kalimat yang diproduksi oleh pelajar terpengaruh oleh struktur bahasa pertamanya. Pada kalimat (3) dapat dilihat bahwa kalimat tersebut tidak berterima bagi penutur asli bahasa Indonesia karena sistem bahasa Indonesia mengenal kata hubung "daripada" sebagai kata hubung perbandingan sedangkan pada kalimat (3) pelajar CLS menggunakan kata hubung "daripada" sebagai kata hubung penanda kontras. Begitu pula pada kalimat (4), pelajar terpengaruh oleh bahasa pertamanya sehingga kalimat yang ia hasilkan tidak berterima bagi penutur asli bahasa Indonesia. Hal tersebut tampak pada konstituen "sudah pernah bermain karawitan banyak tahun".

(5) Sesudah orang laki-laki menari "Kuda Lumping", banyak penari dan orang lain mengalami dimasuki tarian oleh jiwa jahat. $\mathrm{ASC} / \mathrm{P} 3 / \mathrm{K} 2$

(6) Setelah itu, dukun-dukun membuat "majik" supaya orang kesurupan bisa menjadi normal lagi. ASC/P3/K3

Dapat dilihat pula pada kalimat (5) dan (6) bahwa pelajar CLS mengalami interferensi karena kalimat yang dihasilkannya masih terpengaruh oleh struktur kalimat bahasa pertamanya. Pada kalimat (5), dapat dilihat bahwa konstituen “ banyak penari dan orang lain mengalami dimasuki tarian oleh jiwa jahat" merupakan kalimat yang tidak berterima bagi penutur asli bahasa Indonesia karena struktur dan pilihan katanya yang kurang lazim "mengalami dimasuki tarian oleh jiwa jahat" cukup disebut dengan "kesurupan" oleh orang Indonesia. Pelajar CLS tidak menggunakan kata "kesurupan" 
untuk menyebutkan "orang yang kerasukan roh jahat" karena pelajar CLS tidak memiliki fitur semantik tentang kata "kesurupan" sehingga pelajar menggunakan rangkaian pilihan kata "mengalami dimasuki tarian oleh jiwa jahat". Hat tersebut bisa saja terjadi karena budaya asli pelajar CLS kurang mengenal adanya peristiwa "kesurupan" atau "kerasukan". Begitu pula pada kalimat (6), pelajar CLS terpengaruh oleh budayanya untuk menggambarkan peristiwa saat dukun menolong orang yang kesurupan sehingga kalimat yang dihasilkan kurang berterima bagi penutur asli bahasa Indonesia.

(7) Juga, saya belajar banyak tentang pemrosesan teh dari orang yang bekerja di pabrik. $\mathrm{DB} / \mathrm{P} 1 / \mathrm{K} 4$

(8) Saya tidak tahu tentang itu, tetapi sekarang saya mengerti. DB/P1/K5

(9) Untuk tukang pabrik, mereka harus bekerja di malam karena mereka harus menunggu pabrik untuk pekerja lain selesai kerjaan. $\mathrm{DB} / \mathrm{P} 2 / \mathrm{K} 4$

Pada kalimat (7), (8), dan (9), dapat dilihat bahwa pelajar CLS juga mengalami interferensi karena kalimat yang dihasilkan terpengaruh oleh struktur kalimat bahasa pertamanya. Pada kalimat (7) dapat dilihat bahwa pelajar bahasa asing menggunakan kata "juga" di awal kalimat. Jika dalam bahasa Inggris, pelajar CLS bisa menggunakan kata "also" sebagai kata penghubung antarkalimat, namun tidak demikian pada bahasa Indonesia. Akan tetapi, pelajar CLS menggunakan padanan kata "also" untuk menghubungkan antara kalimat sebelumnya dengan kalimat selanjutnya. Sama halnya dengan kalimat (8), pelajar CLS menggunakan struktur kalimat pada bahasa pertamanya dalam menghasilkan kalimat. Penutur asli bahasa Indonesia memahami maksud yang ingin disampaikan oleh pelajar bahasa asing tetapi kalimat tersebut tidak berterima bagi penutur bahasa Indonesia karena struktur kalimat (8) bukan struktur kalimat dalam bahasa Indonesia. Begitu pula pada kalimat (9), dapat dilihat pada konstituen "menunggu pabrik untuk pekerja lain selesai kerjaan" bahwa pelajar CLS terpengaruh oleh struktur bahasa pertamanya.

(10) Pendapat saya, upacara di desa Ngadas adalah kegiatan 
yang paling menarik sampai sekarang di hidup saya. JS/P1/K3

(11) Pertama, 5 cowok mulai menari dengan kuda fiksi selama 30 menit. JS/P2/K1

Pada kalimat (10) dan (11) dapat dilihat bahwa pelajar CLS juga memproduksi kalimat yang strukturnya kurang lazim bagi penutur asli bahasa Indonesia. Dapat dilihat pada kalimat (10), pada konstituen " kegiatan yang paling menarik sampai sekarang di hidup saya" bukan merupakan struktur kalimat dalam bahasa Indonesia sehingga kalimat tersebut tidak berterima bagi penutur asli bahasa Indonesia. Begitu pula pada kalimat (11), pada frasa "kuda fiksi" dapat dilihat bahwa pelajar CLS terpengaruh oleh struktur kalimat bahasa pertamanya sehingga ketika ia menulis, ia menggunakan pilihan frasa "kuda fiksi" bukan "kudakudaan". Hal tersebut bisa saja terjadi karena pelajar CLS tidak memiliki fitur semantik kata "kudakudaan" sehingga pelajar bahasa asing menggunakan pilihan frasa "kuda fiksi" untuk mendeskripsikan "kuda lumping" yang ditunggangi oleh penari.

\section{SIMPULAN DAN SARAN}

Pembelajar CLS seharusnya lebih dituntut lagi untuk memperkaya kosakata dalam bahasa Indonesia. Dengan cara lebih mengenal budaya Indonesia misalnya. Pembelajar CLS juga lebih dikenalkan dengan budaya Indonesia sehingga ia memiliki fitur semantik yang memadai agar bisa mendeskripsikan budaya Indonesia di mata dunia dengan lebih baik. Selain itu, pelajar CLS juga dilatih lebih banyak lagi untuk menulis dalam bahasa Indonesia karena selama ini pelajar CLS hanya ditekankan hanya bisa berkomunikasi dalam bahasa lisan namun tidak dalam bahasa tulisan. Untuk mengurangi interferensi dalam bahasa lisan dan tulis, dengan kegiatan menulis pelajar CLS bisa berlatih lebih banyak untuk mengurangi interferensi.

\section{DAFTAR RUJUKAN}

Brown, H. Douglas. 2007. Prinsip Pembelajaran dan Pengajaran Bahasa. Jakarta: Pearson Education, Inc. 
Hasan, M. Z. 1990. Pengembangan Penelitian Kualitatif dalam Bidang Bahasa dan Sastra. Dalam Aminuddin (Eds.), Karakteristik Peniltian Kualitatif (hlm. 12-25). Malang: YA 3.

Kadarisman, A. Effendi. (Ed). 2009. Mengurai Bahasa Menyibak Budaya. Malang: UM Press.
Pranowo. 1996. Analisis Pengajaran Bahasa. Yogyakarta: Gajah Mada University Press.

Suyitno, I. 2004. Pengetahuan Dasar BIPA: Pandangan Teoritis Belajar Bahasa. Yogyakarta: CV. Grafika Indah 